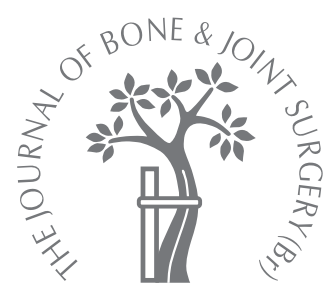

\title{
Neurolysis is not required for young patients with a spontaneous palsy of the anterior interosseous nerve
}

\author{
RETROSPECTIVE ANALYSIS OF CASES MANAGED NON- \\ OPERATIVELY
}

M. Seki,

H. Nakamura,

H. Kono

From Osaka City Sumiyoshi Hospital, Osaka, Japan
M. Seki, MD, PhD, Deputy Director

H. Kono, MD, PhD,

Orthopaedic Surgeon

Department of Orthopaedic Surgery

Osaka City Sumiyoshi Hospital

1-2-16, Higashikagaya,

Suminoe-ku, Osaka 559-0012,

Japan.

H. Nakamura, MD, PhD, Chief Director

Department of Orthopaedic

Surgery

Osaka City General Hospital, 2-

13-22, Miyakojimahondori,

Miyakojima-ku, Osaka 534

0021, Japan.

Correspondence should be sent to Dr M. Seki; e-mail:

mseki@leto.eonet.ne.jp

(c)2006 British Editorial Society of Bone and Joint Surgery doi:10.1302/0301-

$620 \mathrm{X} .88 \mathrm{~B} 12.17700 \$ 2.00$

$J$ Bone Joint Surg $[\mathrm{Br}]$ 2006;88-B:1606-9.

Received 30 January 2006

Accepted after revision 8

August 2006

We studied 21 patients with a spontaneous palsy of the anterior interosseous nerve. There were 11 men and 10 women with a mean age at onset of 39 years (17 to 65).

Pain around the elbow or another region (forearm, shoulder, upper arm, systemic arthralgia) was present in $\mathbf{1 7}$ patients and typically lasted for two to three weeks. It had settled within six weeks in every case. In ten cases the palsy developed as the pain settled. A complete palsy of flexor pollicis longus and flexor digitorum profundus to the index finger was seen in 13 cases and an isolated palsy of flexor pollicis longus in five. All patients were treated without operation. The mean time to initial muscle contraction was nine months $(2$ to 18 ) in palsy of the flexor digitorum profundus to the index finger, and ten months (1 to 24) for a complete palsy of flexor pollicis longus. An improvement in muscle strength to British Medical Research Council grade 4 or better was seen in all 15 patients with a complete palsy of the flexor digitorum profundus and in $\mathbf{1 6}$ of 18 with a complete palsy of flexor pollicis longus.

There was no significant correlation between the duration of pain and either the time to initial muscle contraction or final muscle strength. Prolonged pain was not always associated with a poor outcome but the age of the patient when the palsy developed was strongly correlated. Recovery occurred within $\mathbf{1 2}$ months in patients under the age of $\mathbf{4 0}$ years who achieved a final British Medical Research Council grade of 4 or better. Surgical decompression does not appear to be indicated for young patients with this condition.

Spontaneous atraumatic palsy of the anterior interosseous nerve has been described in association with neuralgic amytrophy, ${ }^{1,2}$ isolated neuritis, ${ }^{3}$ entrapment neuropathy ${ }^{4,5}$ and hourglass-like fascicular constriction. ${ }^{6}$ The aetiology of the condition, however, remains uncertain. Neurolysis of the nerve has been recommended if conservative treatment has not been successful after 12 weeks. ${ }^{7-9}$ Seror $^{10}$ concluded that surgery should not be considered for a year, as late spontaneous recovery can occur. There have also been reports that suggest no difference in outcome between surgical and conservative treatment. ${ }^{11,12}$ Nagano $^{6}$ identified an hourglass-like fascicular constriction of the relevant portion of the median nerve above the elbow: neurolysis yielded good results in such cases. No consensus has been reached about the treatment of this palsy because its aetiology is uncertain. Neither the time to spontaneous recovery, nor the extent to which the nerve will recover if left untreated have been defined. The purpose of this study was to determine the time to spontaneous recovery and the factors which affect it.

\section{Patients and Methods}

We studied 21 patients $(11$ men and 10 women) with a spontaneous palsy of the anterior interosseous nerve who attended the Department of Orthopaedic Surgery of Osaka City University Hospital between May 1988 and October 1999. Their mean age at the time of onset of symptoms was 39 years (17 to 65). The palsy was on the right side in nine patients and on the left in 12. Each patient underwent extensive electromyographic examination of the affected upper limb, sampling the upper fibres of trapezius, infraspinatus, deltoid, biceps, triceps, pronator teres, flexor pollicis longus, pronator quadratus, abductor pollicis brevis, and abductor digiti minimi.

We informed the patients that their palsy was very likely to recover spontaneously and treated them conservatively with vitamin $\mathrm{B}_{12}$ and electrical stimulation therapy. Electromyography was performed every three to five weeks for those who presented with a complete palsy. The appearance of voluntary contraction potentials, usually of very low amplitude, was considered a sign of recovery. Electro- 
Table I. Details of 21 cases of lesions of the anterior interosseous nerve

\begin{tabular}{|c|c|c|c|c|c|c|c|c|c|c|c|}
\hline \multirow[b]{2}{*}{ Case } & \multirow[b]{2}{*}{ Age } & \multirow[b]{2}{*}{ Gender } & \multirow[b]{2}{*}{ Side } & \multirow[b]{2}{*}{ Site of pain ${ }^{*}$} & \multirow[b]{2}{*}{ Duration of pain } & \multirow[b]{2}{*}{ Form of palsy ${ }^{\dagger}$} & \multicolumn{2}{|c|}{$\begin{array}{l}\text { Time to signs of } \\
\text { recovery }\end{array}$} & \multirow[b]{2}{*}{ Follow-up (mths) } & \multicolumn{2}{|c|}{$\begin{array}{l}\text { Final muscle } \\
\text { strength (Medical } \\
\text { Research Council) }\end{array}$} \\
\hline & & & & & & & FDP1 (mths) & FPL (mths) & & FDP1 & FPL \\
\hline 1 & 31 & $\mathrm{~F}$ & $\mathrm{~L}$ & LE $\sim \mathrm{F}$ & 4 wks & FPL-C & $N / A^{\ddagger}$ & 5 & 43 & $\mathrm{~N} / \mathrm{A}$ & $5-$ \\
\hline 2 & 27 & $M$ & $\mathrm{~L}$ & None & None & FPL-C & $\mathrm{N} / \mathrm{A}$ & 7 & 19 & N/A & $5-$ \\
\hline 3 & 41 & M & $\mathrm{R}$ & None & None & FPL-C, FDP1-C & 9 & 9 & 85 & 5 & 5 \\
\hline 4 & 58 & M & $L$ & LE & 1 day & FPL-C & N/A & 11 & 78 & $\mathrm{~N} / \mathrm{A}$ & 5 \\
\hline 5 & 47 & M & $\mathrm{R}$ & SA & 4 wks & FPL-C, FDP1-C & 13 & 13 & 76 & 5 & 5 \\
\hline 6 & 41 & $\mathrm{~F}$ & $\mathrm{R}$ & $\mathrm{RS} \sim \mathrm{E}$ & 3 wks & FPL-C, FDP1-C & 8 & 10 & 67 & 5 & 5 \\
\hline 7 & 65 & $\mathrm{~F}$ & $\mathrm{R}$ & $\mathrm{BS} \sim \mathrm{F}$ & 10 days & FPL-C, FDP1-C & 18 & 22 & 65 & 5 & $5-$ \\
\hline 8 & 51 & $\mathrm{~F}$ & $\mathrm{R}$ & $\mathrm{RE}$ & 4 wks & FPL-C, FDP1-C & 9 & 16 & 63 & 5 & 3 \\
\hline 9 & 30 & $M$ & $\mathrm{~L}$ & LE & 10 days & FPL-C, FDP1-C & 4 & 4 & 60 & 5 & 5 \\
\hline 10 & 54 & $\mathrm{~F}$ & $\mathrm{~L}$ & LE & 10 days & FPL-C & N/A & 24 & 60 & N/A & 3 \\
\hline 11 & 24 & M & $\mathrm{L}$ & $\mathrm{LE} \sim \mathrm{F}$ & 3 wks & FPL-C, FDP1-C & 5 & 6 & 25 & 5 & $5-$ \\
\hline 12 & 17 & $M$ & $\mathrm{R}$ & None & None & FPL-C, FDP1-C & 7 & 7.5 & 30 & 5 & 5 \\
\hline 13 & 45 & $\mathrm{~F}$ & $\mathrm{R}$ & $\mathrm{RE} \sim \mathrm{F}$ & $6 \mathrm{wks}$ & FPL-C, FDP1-C & 2 & 11 & 21 & 5 & 4 \\
\hline 14 & 40 & $\mathrm{~F}$ & $\mathrm{~L}$ & LE & 2 wks & FPL-I, FDP1-C & 8 & N/A & 23 & $5-$ & 5 \\
\hline 15 & 39 & $\mathrm{~F}$ & $\mathrm{~L}$ & LS U & 2 wks & FPL-C, FDP1-C & 16 & 11 & 41 & 5- & 4 \\
\hline 16 & 41 & M & $\mathrm{L}$ & LS U & 1 day & FPL-C & N/A & 6 & 20 & $\mathrm{~N} / \mathrm{A}$ & $5-$ \\
\hline 17 & 29 & M & $\mathrm{R}$ & $\mathrm{RE} \sim \mathrm{F}$ & 2 wks & FPL-C, FDP1-C & 11 & 1 & 19 & 4 & 5 \\
\hline 18 & 39 & M & $\mathrm{R}$ & $\mathrm{RE}$ & 2 wks & FDP1-C & 6 & N/A & 20 & $5-$ & N/A \\
\hline 19 & 48 & $\mathrm{~F}$ & $\mathrm{~L}$ & LS F & 3 wks & FPL-C, FDP1-C & 16 & 16 & 31 & $5-$ & $5-$ \\
\hline 20 & 24 & $\mathrm{~F}$ & $\mathrm{~L}$ & LS F & 2 wks & FPL-C, FDP1-C & 4 & 5 & 21 & 5 & 5 \\
\hline 21 & 32 & $M$ & $\mathrm{~L}$ & None & None & FPL-I, FDP1-I & N/A & N/A & 17 & 5 & 5 \\
\hline
\end{tabular}

* LE, left elbow; F, forearm; SA, systemic arthralgia; RS, right shoulder; E, elbow; BS, bilateral shoulder; RE, right elbow; LS, left shoulder; U, upper arm

† FPL, flexor pollicis longus; C, complete palsy; FDP1, flexor digitorum profundus to the index; I, incomplete palsy $\ddagger \mathrm{N} / \mathrm{A}$, not available

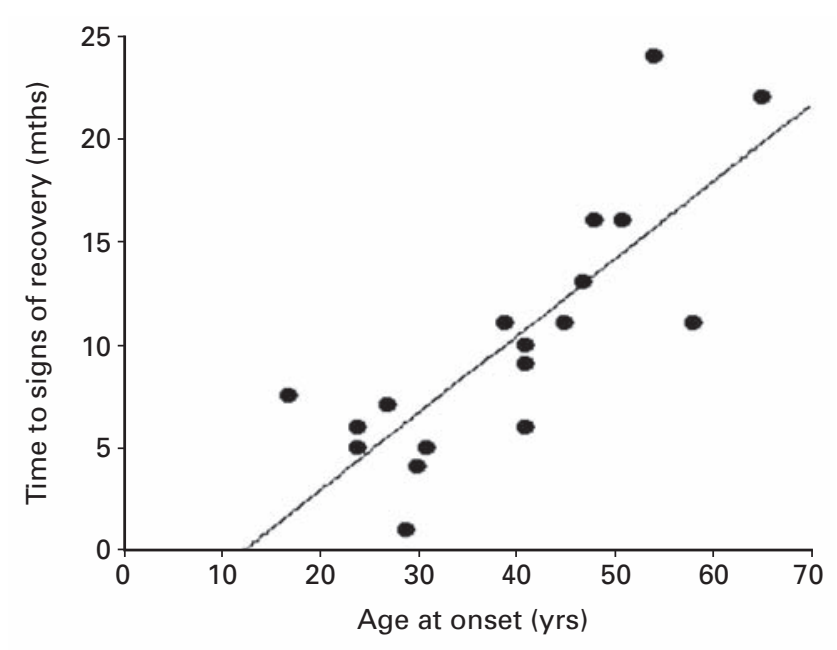

Fig. 1

Correlation between age at onset and time to signs of recovery of flexor pollicis longus.

myography was subsequently carried out at intervals of four to six weeks to monitor the improvement in muscular activity. The mean follow-up was for 42 months (17 to 85). Each patient was assessed for prodromal or associated symptoms, the site and duration of pain, the type of palsy, time to recovery, and the final muscular strength on British Medical Research Council (MRC) grading. ${ }^{13}$

\section{Results}

The details of each case are summarised in Table I. A past history of hepatitis B, surgery for hip replacement and nephrosis was noted in three cases. No patient had cold-like symptoms prior to the onset of palsy. A total of 17 patients complained of pain around the elbow or another region (forearm, shoulder, upper arm, systemic arthralgia) before the onset of paralysis. In three, the palsy developed simultaneously with the onset of pain, in four while the pain persisted, and in ten, simultaneously with the remission of pain. Denervation potentials from the pronator quadratus were observed in every case, except in one where they were also noted from the flexor pollicis longus. The other muscles tested also exhibited multiphasic potentials or giant spikes throughout their extent or in some part of the muscle, suggesting that the palsy was spontaneous and diffuse rather than the result of nerve entrapment.

Every patient eventually showed evidence of recovery. The mean time before the initial signs of muscle contraction appeared in the 15 cases of complete palsy of the flexor digitorum profundus (FDP1) to the index finger was nine months (2 to 18 ), whereas in the 18 cases of complete palsy of the flexor pollicis longus it was ten months (1 to 24). The final grade of FDP1 achieved on MRC grading in the 15 cases of complete palsy was 5 (normal) in ten cases, 5 - in four and 4 in one. The final grade achieved by flexor pollicis longus in the 18 cases of complete palsy was also high (5 in eight cases, 5- in six, 4 in two, and 3 in two). The two 


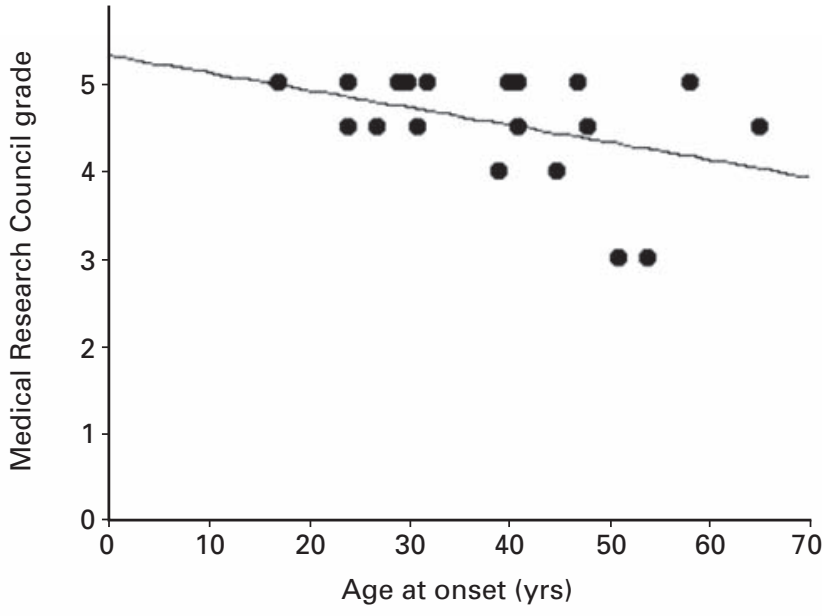

Fig. 2

Correlation between age at onset and final flexor pollicis longus strength.

patients with a final muscle strength of MRC grade 3 were women in their 50s. There was no significant correlation between the duration of pain and either the time to initial contraction of flexor pollicis longus or the final MRC grade. Prolonged pain was not associated with an inferior recovery. All of the patients who developed a palsy before the age of 40 years started to recover within 12 months (Fig. 1). The final muscle strength tended to be lower as the age at onset of the palsy increased, although this relationship was not significant. All of the patients who developed a palsy before the age of 50 recovered muscle strength to MRC grade 4 or better (Fig. 2).

\section{Discussion}

A palsy of the anterior interosseous nerve can result from entrapment neuropathy, neuralgic amyotrophy or an isolated neuritis. ${ }^{1-5}$ Of these, nerve entrapment is the most common cause. ${ }^{4}$ Shantz and Riegels-Nielsen ${ }^{5}$ noted evidence of nerve compression in nine of 15 patients. On the other hand, Nagano ${ }^{14}$ described 31 patients, ten of whom underwent surgical treatment. He found only one with apparent nerve compression, and concluded that although entrapment neuropathy is one cause of this palsy, its incidence is low. In our study, extensive electromyographic studies revealed diffuse neurogenic changes, including denervation potentials in markedly weakened muscle, and multiphasic potentials in muscles free of notable weakness. Consequently, it seems unlikely that nerve compression was the cause of the palsy. These findings, combined with the high percentage of patients with premonitory pain, suggests that neuralgic amyotrophy was responsible for the palsy in the patients studied.

The treatment of spontaneous palsy of the anterior interosseous nerve is controversial, principally because the con- dition is rare. Some investigators have recommended conservative treatment for up to one year, ${ }^{10,15}$ but others advocate neurolysis if no recovery has taken place within three months. ${ }^{7-9}$

In this study we followed all patients with electromyographs at intervals of three to five weeks. As long as denervation potentials could be recorded ${ }^{13}$ we were satisfied that no irreversible muscle fibrosis was taking place, and that conservative treatment could continue. When polyphasic potentials with low amplitude appeared we considered this to be evidence of nerve recovery and told our patients of this to relieve their natural anxiety.

Our findings suggest that a 'wait and see' policy can be adopted for spontaneous palsy of the anterior interosseous nerve even when paralysis is complete.

We found that the time to initial muscle contraction correlated significantly with the age of the patient. Recovery was noted within one year in all patients who developed the condition before the age of 40 years. The correlation between the age at onset and the final muscular strength was not significant. However, when paralysis occurred before the age of 50 years, muscular strength recovered to MRC grade 4 or better in every case.

In 2000, Tsukahara et $\mathrm{al}^{16}$ found that when 12 hands in 11 patients were treated conservatively, the mean length of time required for recovery of muscular strength to MRC grade 2 or higher was three months for a teenager, 20 months for three patients over 30 years, 19.5 months for four patients over 40 years, 13 months for two patients over 50 years, and 25 months for two patients over 60 years. Seror ${ }^{10}$ described 14 cases of palsy of the anterior interosseous nerve and noted that a 63-year-old man failed to recover in 21 months. Yamamoto et $\mathrm{al}^{17}$ and Yamamoto, Tajiri and Yamamoto ${ }^{18}$ noted two patients, a 69-year-old woman and a 73-year-old man, in whom recovery was not achieved with conservative therapy. We recommend nonoperative treatment for patients under 40 years of age.

No benefits in any form have been received or will be received from a commercial party related directly or indirectly to the subject of this article.

\section{References}

1. Parsonage MJ, Turner JWA. Neuralgic amyotrophy: the shoulder-girdle syndrome. Lancet 1948;1:973-8.

2. England JD, Sumner AJ. Neuralgic amyotrophy: an increasingly diverse entity. Muscle Nerve 1987;10:60-8.

3. Kiloh LG, Nevin S. Isolated neuritis of the anterior interosseous nerve. Br Med J 1952;1:850-1.

4. Collins DN, Weber ER. Anterior interosseous nerve syndrome. South Med J 1983;76:1533-7.

5. Shantz K, Riegels-Nielsen P. The anterior interosseous nerve syndrome. J Hand Surg [Br] 1992;17:510-12.

6. Nagano A. Spontaneous anterior interosseous nerve palsy. J Bone Joint Surg [Br] 2003;85-B:313-18.

7. Spinner M. The anterior interosseous nerve syndrome: with special attention to its variations. J Bone Joint Surg [Am] 1970;52-A:84-94.

8. Nigst H, Dick W. Syndromes of compression of the median nerve in the proximal forearm (pronator teres syndrome; anterior interosseous nerve syndrome). Arch Orthop Trauma Surg 1979;93:307-12.

9. Hill NA, Howard FM, Huffer BR. The incomplete interosseous nerve syndrome. J Hand Surg [Am] 1985:10:4-16. 
10. Seror P. Anterior interosseous nerve lesion: clinical and electrophysiological features. J Bone Joint Surg [Br] 1996;78-B:238-41.

11. Sood MK, Burke FD. Anterior interosseous nerve palsy: a review of 16 cases. J Hand Surg [Br] 1997;22-B:64-8.

12. Nakano KK, Lundergan C, Okihiro MM. Anterior interosseous nerve syndromes diagnostic methods and alternative treatments. Arch Neurol 1977;34:477-80.

13. Mumenthaler M, Schliack H. Peripheral nerve lesions: diagnosis and therapy. New York: Thieme, 1991:83.

14. Nagano A. Anterior interosseous nerve palsy. J Jpn Soc Surg Hand 1987;3:894-7 (in Japanese).
15. Futami T, Kobayashi A, Tadano I, Wakita R, Ohtsoka H. Treatment of anterior and posterior interosseous nerve syndrome: conservative treatment. J Jpn Soc Surg Hand 2002:19:111-14 (in Japanese).

16. Tsukahara T, Wada T, Kitamura M, Aoki M, Ishii S. Natural history and long-term prognosis of anterior interosseous nerve palsy. J Jpn Soc Surg Hand 2000;17:411-13 (in Japanese).

17. Yamamoto S, Nagano A, Yamamoto S, Kawano H, Okinagowa S. Prognosis of spontaneous anterior idiopathic nerve palsy: comparison between the results of interfascicular neurolysis and treatment. J Jpn Soc Surg Hand 1998;15:433-6 (in Japanese).

18. Yamamoto S, Tajiri Y, Yamamoto N. Prognosis of spontaneous anterior interos seous nerve palsy. J Jpn Soc Surg Hand 2002;19:193-5 (in Japanese). 